\title{
Educação popular, saúde comunitária e apoio social numa conjuntura de globalização
}

\author{
Popular education, community health, and social \\ support in a context of globalization
}

Victor Vincent Valla 1

\footnotetext{
1 Departamento de Endemias Samuel Pessoa, Escola Nacional de Saúde Pública, Fundação Oswaldo Cruz. Rua Leopol do Bulhões 1480, térreo, Rio de Janeiro, RJ 21045-900, Brasil.
}

Abstract The author discusses difficulties experienced by working-class groups in a crisis context, relating to the demands they make on authorities. Popular participation has traditionally referred to activities resulting in pressure on authorities for i mproved basic services. One can contend that activities commonly known as popular education and community heal th are currently at a stalemate. The social support theory is proposed as a form of not only discussing the crisis in health services, but also the heal th model as being basically curative. In this sense, concepts such as "control over one's life", "I ife making sense", and "soli darity" are discussed as important factors for prevention and maintenance in the field of heal th education. Although it was a context of crisis which led to the discussion of the social support theory, the latter's value does not depend on such a context.

Key words Health Education; Social Support; Health Services; Public Health

Resumo O autor discute as dificuldades enfrentadas pel as classes populares com relação às reivindicações aos governos numa conjuntura de crise. Dentro da concepção clássi ca de participação popular, é possí vel que as práticas de educação popular e saúde comunitária se encontrem num impasse. A teoria do apoi o social é proposta como forma de discutir a crise dos servi ços,como também o modelo de saúde essencial mente curativo. Neste senti do, estão ressaltadas i déi as tai s como a rel ação corpo-mente no processo saú de doença, bem como a necessi dade de questionar a hegemonia médica neste mesmo processo. Categorias como sentido da vida, controle sobre a vida e sol i dariedade são di scuti dos como fatores importantes para a prevenção e manutenção no campo de educação e saúde. Embora fosse um contexto de crise que suscitasse a discussão da teoria de apoio social, seu valor independe de uma conjuntura de crise.

Palavras-chave Educação em Saúde; Apoio Social; Serviços deSaúde; Saúde Pública 


\section{Introdução}

Este trabal ho visa relacionar os temas de educação popular e saúde comunitária com o de apoio social e, para isso, apresenta al guns dos resultados parciais de uma investigação mais ampla desenvolvida durante os estudos de pós-doutorado do autor (Valla, 1996a). A investigação em questão tem como um dos seus eixos principais a discussão de educação popular e saúde comunitária à luz da conjuntura de globalização. $\mathrm{O}$ autor tem como um dos seus pressupostos que a perplexidade em face da questão da globalização, questão esta que atinge a sociedade como um todo, mas em particular os profissionais de educação e saúde, indica a necessidade de explorar novas pistas de investigação.

A forma em que o processo

de globalização se apresenta

na América Latina

Nos dias 16 e 17 de fevereiro de 1996, políticos e intelectuais se reuniram na Cidade do México e, com o apoio da Organização das Nações Unidas (ONU), debateram a seguinte questão: Qual o projeto de reforma do Estado e de desenvolvimento econômico alternativo à economia e à política hoje hegemônicas na América Latina? Independentemente da sua origem política, a grande maioria dos participantes observaram que os governos federais tendem a aplicar medidas semelhantes: privatizações selvagens, políticas compensatórias para os pobres, sem, no entanto, pretender incluí-los na sociedade formal; a redução da capacidade indutora e reguladora do Estado e a social ização das eventuais perdas do capital financeiro. Os participantes do debate chamaram a atenção para o que seja possivelmente a principal contradição do processo de globalização: se, de um lado, cada política de ajuste resulta num aumento de pobreza e desemprego em cada país, de outro lado, a lógica da globalização está longe de oferecer uma solução, pois exige a inversão de grandes massas de capital concentradas para integrar a economia nos padrões competitivos pautados pela revolução digitalinformática. E, finalmente, a constatação de que os grandes meios de comunicação tendem a reforçar essas medidas com uma nova cul tura despolitizante que procura convencer a sociedade de que o processo de globalização não deixa outra saída a não ser resignar-se à "exclusão social” como inevitável (Genro, 1996).
A verba pública, reivindicações da sociedade civil e a proposta do "duplo caminho" peruano

As propostas de educação popular e de saúde comunitária têm sido vistas com freqüência de forma ambígua. Para alguns, são formas de organização e politização populares, que podem até apontar para reivindicações diante da inoperância do Estado, enquanto, para outros, são formas de desenvolver trabal hos que seriam da respon sabilidade governamental, e, neste sentido, ajudam os governos a reduzirem os seus gastos. Quantos a este último ponto, tal crítica ajuda a entender por que muitos tendem a ver os trabalhos de saúde comunitária como um serviço de saúde de segunda classe, para os pobres, que, no fim, permite que mais dinheiro público sobre para atender parcelas da sociedade de mel hores condições de vida. Na realidade, atrás dessa discussão, há uma outra que aponta para as formas desiguais de distribuição do dinheiro público na sociedade brasileira: de um lado, grandes somas dos impostos dirigidos a grandes projetos apoiados pel os capitais nacionais e internacionais (Valla \& Stotz, 1992), e, de outro, o pouco que sobra para os serviços básicos necessários para a reprodução da força de trabalho (Valla, 1997a).

Até recentemente, a proposta hegemônica entre aqueles que se preocupam com a qualidade e quantidade dos serviços básicos e, portanto, com o destino do dinheiro público era a de reivindicação e pressão sobre os governantes (Valla, 1997b). Embora se julgue que tal proposta seja correta, o que se observa em quase toda a América Latina é uma certa perplexidade quanto aos resultados obtidos. O rígido controle fiscal exercido pelo Governo Federal e, conseqüentemente, pelos estados e municípios, como também o forte monitoramento que o Fundo Monetário Internacional e o Banco Mundial exercem sobre as contas brasileiras geram um ambiente de penúria e controle de tal modo, que os governantes contam com estes limites para poder ignorar as reivindicações dos setores organizados da sociedade ci vil de caráter popular.

A recente epidemia de cólera no Peru, por exemplo, teve como desfecho uma surpreendentemente baixa taxa de mortalidade, mas muito mais em razão da iniciativa dos grupos populares, do que por causa dos investimentos do governo peruano. Simbolicamente denominado o "duplo caminho", este movimento, de um lado, cobrou do governo o que seria da sua responsabilidade, e, de outro, quando percebeu que o governo não respondia com os re- 
cursos necessários para combater adequadamente a epidemia, implementou uma política própria de mutirão para salvar os atingidos (Valla, 1997b).

Na última instância, o que está em discussão é a possibilidade de um caminho complementar ao das reivindicações e demandas para uma melhor distribuição do dinheiro público, não porque tal política não seja justa e legíti ma, mas porque pode não ser viável politicamente. O "duplo caminho" não abre mão da reivindicação como política, mas questiona a “via única” nessa conjuntura de globalização.

Outra explicação para a perplexidade que assola políticos, intelectuais e profissionais de educação e saúde é a da natureza do Estado provedor (Moisés, 1982). A baixíssima qualidade de vida de uma grande parte da população brasileira justifica em grande medida a noção do Estado provedor. Nada mais justo do que exigir que os impostos sejam devolvidos à sociedade como um todo na forma de serviços públicos de qualidade. Propor que o poder público ofereça menos do que isso é propor que as condições mínimas de vida não sejam garantidas para toda a população. Mas é possível também questionar se a maneira como o Estado oferece todos os seus serviços ao público é sempre benéfica para o mesmo. A medicalização do fracasso escolar é um exemplo que ilustra bem este ponto (Collares \& Moisés, 1995; Collares et al., 1985; Valla \& Hollanda, 1995).

O impasse criado pela crise de saúde no Brasil

Independentemente da conjuntura atual de políticas neoliberais no Brasil e a conseqüente crise na área de saúde, há uma questão anterior que é comum a alguns países da América Latina. Trata-se do compromisso formal assumido por governos a fim de garantir uma assistência médica universal e gratuita às suas populações. À medida que haja condições mínimas de higiene e alimentação para uma parte considerável de qualquer população, a tendência é que menos crianças morram antes de completar um ano, e que mais adultos ultrapassem a idade de 65 anos. E justamente porque as condições de higiene e alimentação são mínimas é que os problemas conseqüentes de saúde oneram ainda mais os recursos disponíveis para a área de saúde pública. No caso do Brasil, tal quadro é agravado pelos baixos salários e precárias condições de trabalho oferecidos aos profissionais de saúde, dessa forma levando-os a deixar o serviço público. As longas filas que se formam, tanto as dos centros de saúde nas madrugadas, como as de toda hora nos hospitais públicos, criam uma situação que torna a "escolha de Sofia" um fenômeno freqüente.

Um problema que atinge mil hões de brasileiros, por exemplo, são as múltiplas expressões de saúde mental: cobrindo uma gama de sintomas que vão desde o que a classe média se refere como "ansiedade" ao que as classes populares chamam de "nervos". Dados recentes da Argentina indicam que mais de $50 \%$ dos medicamentos consumidos pela população são psicofármacos (Bermann, 1995). É de se perguntar, mesmo que o sistema de saúde no Brasil estivesse funcionando satisfatoriamente, se seria possível atender todos esses casos adequadamente.

É claro que, em vista do quadro anteriormente descrito, é necessário trabalhar para que setores da sociedade civil preocupados com a saúde no Brasil se organizem e demandem mais investimentos dos governantes para contornar a crise. Entretanto, a profunda crise daí decorrente deve estimular reflexões e proposições capazes de redimensionar as relações entre o Estado e a sociedade, particularmente para favorecer a ampla maioria dos que se encontram excluídos dos benefícios da riqueza e do bem-estar.

Stotz, chama atenção para a necessidade de superar a mera defesa do papel do Estado em prover diretamente ou em regular a oferta privada (contratada ou autônoma) de serviços. Para que tais serviços contemplem de fato as necessidades sociais das populações, precisam levar em conta, obrigatoriamente, o que as pessoas pensam sobre seus próprios problemas e que soluções espontaneamente buscam. A história nunca começa com o contato dos profissionais dos serviços com as suas clientelas. A história é anterior: há um passado que ainda vive, em sua virtualidade, no presente e está referido às experiências acumuladas em uma gama amplamente diversificada de alternativas, bem como às lutas moleculares ou coletivas que enraízam formas de pensar e agir. É esta experiência que precisa ser resgatada pelos serviços, pel os profissionais, técnicos e planejadores. Ela é o crisol de uma nova compreensão da produtividade social, porque também no âmbito dos serviços sociais deve-se trabalhar com a premissa de uma escassez relativa de recursos. Uma relação interativa entre serviços e populações tem o significado, portanto, de um novo ponto de partida para equacionar, no contexto dramático em que vivemos, universalidade com equidade e eficiência (Valla \& Stotz, 1997). 
A perplexidade certamente inclui, de um lado, uma preocupação com a dimensão gigantesca do problema a ser superado e, de outro, o reconhecimento do compromisso de "fazer algo", embora tendo como referencial uma sociedade civil debilitada. Possivelmente, a sensação de estar "batendo em ponta de faca" seja o sinal de que a discussão chegou a um certo impasse. Não que o fato de reivindicar uma política mais coerente dos governantes não seja necessário, mas talvez haja outras dimensões do problema a serem vistas. Nesse sentido, é possível também que as categorias utilizadas para discutir os trabalhos de educação popular e saúde comunitária sejam inadequadas, pois "écomum confundir a questão quenós el aboramos com o método que utilizamos para obter a resposta... (e) a maneira em que se formula uma questão determina em que di reção se busca a resposta" (Cassell, 1976a:37).

Introduzindo a questão do apoio social como subsídio para o debate

O que se propõe é lançar mão de um debate da saúde pública que ocorreu com muito intensidade nos Estados Unidos na década de 80. O de bate em torno do que se chama social support, isto é, apoio social, está relacionado com a crise de saúde pública naquele país, mas que foi desenvolvido numa conjuntura diferente à da globalização no Brasil. Neste sentido, propõe-seuma releitura do debate norte-americano, mas à luz dos aspectos particulares da sociedade brasileira.

Apoio social se define como sendo qualquer informação, falada ou não, e/ ou auxílio material oferecidos por grupos e/ ou pessoas que se conhecem eque resultam em efeitos emocionais e/ ou comportamentos positivos. Trata-se de um processo recíproco, ou seja, que gera efeitos positivos tanto para o recipiente, como também para quem oferece o apoio, dessa forma permitindo que ambos tenham mais sentido de controle sobre suas vidas. Desse processo se apreende que as pessoas necessitam umas das outras (Minkler, 1985). Essencialmente, o debate acerca da questão do apoio social se baseia em investigações que apontam para o papel destena manutenção de saúde, na prevenção contra doença e como forma de facilitar a conval escença.

Uma das premissas principais da teoria é a de que o apoio social exerce efeitos diretos sobre o sistema de imunidade do corpo, ou como buffer, no sentido de aumentar a capacidade de as pessoas lidarem com o stress (Bermann, 1995). Outro possível resultado do apoio social seria sua contribuição geral para a sensação de coerência da vida e o controle sobre a mesma, que, por sua vez, afeta o estado de saúde de uma pessoa de uma forma benéfica (Cassell, 1976a).

Inversamente, então, poder-se-ia dizer que, quando o apoio social diminui, o sistema de defesa é afetado, fazendo com que o indivíduo se torne suscetível à doença. Em momentos de muito stress, o apoio social contribui para manter a saúde das pessoas, pois desempenha uma função mediadora. Assim, permite que as pessoas contornem a possibilidade de adoecer como resultado de determinados acontecimentos, como, por exemplo, a morte de alguém da família, a perda da capacidade de trabalhar, ou um despejo da casa onde se reside por muitos anos. Uma decrescente oportunidade com outras pessoas, ou de participar no processo de tomada de decisões podem ter o efeito de contribuir para um diminuído sentido de controle, que, por sua vez, afeta a morbidade e mortalidade (Minkler, 1992; Gottlieb, 1983).

Cassell levanta a hipótese de que, no caso de al gumas enfermidades, lugares de alta densidade populacional não aumentam a suscetibilidade à doença por causa da densidade em si. Uma sensação de não poder controlar sua própria vida juntamente com a sensação de isolamento podem ser relacionados com o processo de saúde-doença. A proposta do apoio social sugere que as conseqüências dos problemas sociais, como desemprego, violência, por exemplo, não necessariamente afetam da mesma forma todas as pessoas neles envolvidas. Estudos têm demonstrado que os apoios disponíveis de determinadas organizações sociais podem influir beneficamente, no sentido de proporcionar fatores de proteção contra o aparecimento de doenças, oferecendo melhorias de saúdefísica, mental e emocional (Cassell, 1974). Trata-se da noção de empowerment, isto é, um processo pelo qual indivíduos, grupos sociais e organizações passam a gan har mais controle sobre seus próprios destinos (Minkler, 1985).

Logo, um envolvimento comunitário, por exemplo, pode ser um fator psicossocial significante na melhoraria da confiança pessoal, da satisfação com a vida e da capacidade de enfrentar problemas. A participação social pode reforçar o sistema de defesa do corpo e diminuir a suscetibilidade à doença.

Uma discussão latente atrás da questão do apoio social

A proposta do apoio social tem suas raízes no interior de uma outra discussão: a do desenvolvimento da medicina no Ocidente. Não há 
dúvida de que se trata de um debate, não somente antigo, mas também de literatura extensa. Mesmo reconhecendo isso, propõe-se, para fins deste trabalho, apresentar algumas das idéias que serviriam como subsídios para a discussão do apoio social .

O desenvolvimento da medicina volta, pelo menos, até o ano de 400 a.C., quando os médicos relacionados com o pensamento de Hipócrates, no esforço de se desvincular de qualquer conexão com medicina popular e superstição, detiveram-se às mensurações objetivas, diminuindo a importância da palavra do paciente. Talvez tenha sido uma das primeiras manifestações que apontava para uma concepção de medicina que separava o corpo da mente. Séculos mais tarde, uma forma mais explícita de expressão, o homem entendido como ser dual, podia ser vista no esforço dos cientistas do século XVII, agrupados em torno do debate encabeçado por Descartes. A dualidade cartesiana foi também uma solução para um impasse político que emperrava o desen volvimento da ciência - a posição da Igreja Católica. Com a divisão do homem em mente e corpo como realidades distintas, foi possível a ciência ficar com o corpo e a filosofia com a mente. Se, de um lado, foi possível superar o impasse político, de outro, a herança foi a de uma ciência cujo papel era o de medir o finito, para a qual a doença se torna o centro de atenção e o doente ocupa um lugar secundário (Cassell, 1976a).

O desenvol vimento da medicina no Ocidente tem ocasionado um debate de muitos anos entre dois campos: os que se intitulam fisiologistas e os ontologistas. Os primeiros mantêm que a doença é o resultado de um estado de desequilíbrio dos "humores" do paciente, isto é, de uma relação desequilibrada entre o homem e o meio ambiente. Como se pode ver, os fisiologistas foram os precursores da teoria do miasma, ou seja, de que as doenças surgem do ar e da água estagnados e contaminados. No outro lado dessa disputa intelectual e política que perpassa séculos, estão os ontologistas, que acreditavam que as doenças tinham uma vida própria e que os corpos das pessoas doentes eram invadidos por elas. Um pensamento que, no século XIX, desdobrar-se-ia na teoria vitoriosa do germe, com a conseqüente derrota dos fisiologistas (Cassell, 1976a).

Vale a pena destacar duas perdas com a derrota dos fisiologistas: tornam-se secun dários o doente e o saneamento do meio ambiente, fazendo, dessa forma, com que a doença e sua eliminação por meio da vacinação e/ ou medicamentos surjam prioritários na medicina. Se os efeitos negativos dessa vitória não têm sido tão grandes nos países do capitalismo avançado, têm sido desastrosos, em compensação, em países como o Brasil, com suas valas negras e abertas e sua falta perene de água em muitas favelas e bairros pobres.

Hoje em dia, o debate continua acerca das mesmas questões, mas obviamente em conjunturas diferentes. É claro, porém, que as pessoas que propõem a teoria do apoio social são herdeiros dos fisiologistas. Cassell (1976a) afirma, por exemplo, que há poucas evidências históricas para afirmar que as melhorias na saúde de populações se devem aos médicos e à ciência médica. Cita, como exemplo, a queda da mortalidade infantil nos Estados Unidos durante as primeiras décadas do século XX. A grande redução do complexo diarréia-pneumonia ocorreu antes do uso de qualquer droga antimicrobial ou vacina, e a queda ocorreu numa época em que melhoravam os padrões de educação, nutrição e saneamento básico.

Antonovsky (1979), por sua vez, demonstra que os casos de tuberculose tinham caído no mundo em 95\%, de 1945 a 1973, ao contrário da afirmação de que tal queda se dera com a introdução de drogas específicas. Na realidade, o declínio vinha ocorrendo por mais de cem anos, e, na Inglaterra e no País de Gales, por exemplo, no período de 1850 a 1971, apenas $14 \%$ do declínio da mortalidade causada por tuberculose ocorreram após a introdução de drogas.

Mas, se os herdeiros dos fisiologistas e proponentes da teoria do apoio social dão um valor muito grande para a questão do meio ambiente como uma questão-chave para a explicação do processo saúde-doença, enfatizam também que se trata de uma relação do meio ambiente com o homem integral, de corpo e mente. Exemplificando, poder-se-ia questionar que ou o sofrimento é exclusivamente subjetivo e, nesse sentido, não cabe dentro do domínio da medicina, ou é exclusivamente identificado com a dor física. Assim, no caso dos moribundos, por exemplo, tanto os pacientes, como as suas famílias e amigos, não fazem uma distinção entre o sofrimento físico e não físico da mesma maneira que os médicos fazem. E, mesmo no caso de quem convalesce, o sofrimento não ocorre exclusivamente durante o decorrer de uma doença, mas também freqüentemente como resultado do seu tratamento (Cassell, 1976b).

A medicina, na sua expressão no Ocidente, é pouco sensível para a expressão humana. É muito comum na vida das pessoas sentimentos intensos em relação a grupos, idéias e cau- 
sas mai ores, que vão além da existência dos indivíduos - uma evidência da dimensão universal da transcendência. É por essa razão que se sofre tanto com a perda das pessoas amadas, ou com os sentimentos de abandono, traição, medo, ou a perda de um trabalho de uma vida. A recuperação de um acontecimento que gerou muito sofrimento freqüentemente implica ajuda, e é possível que quem perdeu parte de si possa ser mantido pelas qualidades pessoais de outras pessoas, até que sua parte perdida se recupere. A transcendência é provavelmente a forma mais eficaz em que as pessoas afetadas por perdas são restauradas à integridade (Cassell, 1976b).

\section{Tecendo as partes e sugerindo pistas}

A proposta de apoio social não seria uma solução pontual para a crise, mas o trampolim para rever a relação da saúde com a questão médica. Se, de um lado, o apoio social oferece a possibilidade de realizar a prevenção através da solidariedade e apoio mútuo, de outro, oferece também uma discussão para os grupos sociais sobre o controle do seu próprio destino e autonomia das pessoas perante a hegemonia médica, através da "nova” concepção do homem como uma unidade (Tognoni, 1991; Valla, 1997b).

É nesse sentido que a discussão do apoio social, dentro de um contexto de uma relação homem integral e meio ambiente, cabe como questão nos currículos das escolas públicas, nas plataformas dos partidos políticos, e, em particular, em três áreas relacionadas com educação popular e saúde comunitária: as associações de moradores, as igrejas e os agentes de saúde.

Com relação às associações de moradores, levanta-se a hipótese de que o chamado "retrocesso" dos movimentos de bairros efavel as não se deve exclusivamente à recusa das autoridades em atender as demandas. Embora, como foi afirmado anteriormente, certamente haja elementos de verdade nesse argumento, pergunta-se se a proposta de somente reivindicar ao poder público, juntamente com a militância que a acompanha, não acabam sendo propostas insuficientes para uma grande parcela da população. Ou seja, explicaria em parte a freqüente presença de pequenos grupos militantes que atuam de uma forma isolada. Cabe perguntar se a proposta de apoio social não seria uma forma menos pontual, mas, ao mesmo tempo, mais duradoura, de lidar com a questão da saúde. De um lado, a busca de compreender quais problemas de saúde têm soluções no âm- bito da própria comunidade; de outro lado, a possibilidade de socializar a concepção de autonomia e do controle sobre o seu próprio destino, de perceber que a "eficáci a médica... não é o aspecto mais si gnificante de qual quer sistema desaúde" (Bastien, 1992).

Na língua portuguesa, a palavra "comunidade" tem se transformado numa referência às populações pobres, moradores de favelas, de bairros de infra-estrutura precária. Mas não é somente a língua que tem modificado a idéia de comunidade; as mudanças sócio-econômicas da vida urbana brasileira, seja pelo crescimento das favelas ao ponto de não comportar uma comunidade só, seja pelo grau de violência nestes locais, também limitam o desenvolvimento das organizações populares (Centro de Defesa dos Direitos Humanos Bento Rubião, 1994). Esta deve ser considerada como uma das explicações para o extraordinário crescimento da presença das classes populares nas igrejas de todas as religiões, mas, principalmente, nas chamadas evangélicas ou pentecostais (Barrose Silva, 1995).

Se não há como negar que alguns pastores também visam à manipulação política e/ou enriquecimento próprio às custas dos fiéis, tais argumentos, por si, não oferecem subsídios suficientes para compreender por que tantas pessoas das classes populares procuram as igrejas. Explícita ou implicitamente, a questão de saúde está presente, seja pela busca da cura, seja pela idéia subjacente do apoio social. Levantase a hipótese, inclusive, de que as igrejas, mediante a proposta espiritual e/ ou religiosa, oferecem aos fiéis um sentido de solidariedade, respeito e prestígio, como também um sentido de coerência da vida e controle sobre a mesma (Eng et al., 1985). Certamente, cabe uma investigação sobre o apoio social que as igrejas proporcionam e como isso se relaciona com a manutenção e/ ou recuperação da saúde, seja pela prevenção, seja pela cura.

Uma terceira pista trata dos agentes de saúdee/ ou agentes comunitários: geralmente muIheres, mas não exclusivamente, são hoje uma realidade no Brasil. Ainda muitas vezes sem situação trabalhista resolvida, são uma espécie de intermediários entre a população de uma favela ou bairro periférico e os serviços de saúde. Freqüentemente recebem al gum ti po de treinamento e são, às vezes, as únicas pessoas, juntamente com os curandei ros, que se dedicam às tarefas de saúde com os moradores desses locais de difícil acesso ( Valla \& Siqueira, 1995).

Na realidade, o termo "agente de saúde", por ser utilizado de uma forma genérica no mundo inteiro, como, por exemplo, community 
health workeragentes, agentes desalud comunitario, acaba escamoteando sua expressão local em determinadas conjunturas sócio-econômicas.

No Rio de Janeiro, num encontro de agentes de saúde, foi confirmado que, em algumas favelas, dado o grau de violência, eles são o único vínculo de saúde com os moradores (Oliveira \& Cardoso, 1995). Na região Andina do Peru, no combate às endemias numa conjuntura de globalização, os estreitos limites da proposta biomédica são contrapostos por agentes de saúde comunitários; lá, a questão da cultura e religiosidade populares oferecem soluções superiores por intermédio do apoio social (Wong-Un, 1997). Algumas experiências na Bolívia têm demonstrado a importância da etnomedicina, para a qual as relações sociais, a questão religiosa, a doença e a manutenção da saúde fazem parte de um tecido só. Nesse sentido, os resultados obtidos por alguns curandeiros bolivianos indicam que métodos aparentemente "mági cos" têm um forte efeito psicológico, afetando, assim, de uma forma benéfica, os sistemas de imunidade de algumas pessoas doentes da população (Bastien, 1992).

Tais experiências lembram outras transmitidas pelas agentes de saúde do Grupo Sementinha, das favelas da região da Leopol dina, no Rio de Janeiro, onde o trabalho com chás e xaropes de ervas, como também o uso da "reza" têm produzido resultados benéficos para os moradores (Informativo do CEPEL, 1993).

\section{Conclusão}

Este artigo, embora desenvolva uma discussão sobre educação popular, saúde comunitária e apoio social, aponta também para a crise da saúde no Brasil. Nesse sentido, discorre sobre o agravamento de um quadro já crítico do acesso da população aos serviços de saúde. Ou seja, não há garantia de que todos terão assistência, e, para aqueles que serão atendidos, o peso das demandas e as expectativas da população fazem com que o atendimento seja necessariamente medicalizante, quase exclusivamente visando apenas ao corpo.

O que se propõe, então, é abrir um debate sobre como enfrentar o dilema. Reivindicar uma política de saúde melhor coloca o debate no centro da questão orçamentária, certamente necessária, mas ainda dentro de um enfoque excessivamente curativo e sem garantia de tratamento universal e igualitário. O impasse é propício à proposta de um novo ol har na direção da saúde comunitária e educação popular.
Não numa perspectiva de "quebra-galho" para uma população tida por muitos como "descartável", mas para repensar a questão da saúde com base na crise.

As propostas da educação popular e saúde comunitária são vistas sob a perspectiva do apoio social, e, assim, a questão aponta para o mesmo dilema da globalização e do emprego. A não ser que haja uma mudança substancial na sociedade brasileira, haverá emprego somente para uma parcela da população, havendo, paralelamente, assistência na área de saúde somente para uma parcela.

O impasse criado exige pressão organizada sobre os governantes, mas exige também que se pergunte se se quer, num futuro hipotético, uma otimização do tipo de política de saúde que aí está hoje. A introdução da questão do apoio social já traz implícita a posição de que dificilmente o quadro descrito acima vai se modificar no futuro próximo, a não ser para tornar o quadro de saúde mais difícil para a maioria da população.

Todavia, ao se propor a questão do apoio social, não se busca apenas uma resolução pontual para os chamados "excluídos"; embutido na proposta está o questionamento sobre se tal proposta não merece ser considerada também exclusivamente por seus méritos. 0 raciocínio assemelha-se a um outro sobre ervas medicinais: interessam porque são mais baratas do que os medicamentos, ou interessam por seu próprio valor?

Dessa forma, a crise e o impasse a que se chegou é que permitem que o debate sobre o apoio social seja relevante. É claro que, na atual conjuntura, as políticas de solidariedade e apoio mútuo, isto é, do apoio social, representarão as únicas soluções para muitos dos "excluídos", en quanto representarem soluções alternativas para alguns profissionais. Mas cabe perguntar também se a proposta do apoio social, com suas implicações em aumentar as defesas da imunidade do corpo, não é relevante justamente porque leva em conta que os homens não são apenas "corpos" a serem curados e porque o estado de saúde daqueles representa uma relação integrada entre o corpo e a mente. $E$, embora seja a crise a obrigar que se lance mão desta proposta, não é significativo que a proposta de apoio social necessariamente implica uma participação comunitária que é necessariamente democrática?

Na realidade, como afirma Wong-Un (1997), não é a crise que aponta as propostas da solidariedade e do apoio mútuo para os excluídos; eles já desenvolvem tais práticas há muito tempo. É mais provável que, no espírito de que “a 
crise de compreensão é nossa" (Valla, 1996b), a descoberta da proposta do apoio social seja mais importante para aqueles profissionais de educação e saúde preocupados com o destino dessas parcelas da chamada população "descartável".

\section{Referências}

ANTONOVSKY, A., 1979. Health, Stress and Coping. San Francisco: Jossey-Bass Publishers.

BARROS E SILVA, F., 1995. Pesquisadora vê democracia religiosa. Folha de São Paulo, São Paulo, 26 dez. Caderno I, p.6.

BASTIEN, J., 1992. Drum and Stethoscope. Integrating Ethnomedicine and Biomedicine in Bolivia. Salt Lake City: University of Utah Press.

BERMANN, S., 1995. Trabajo Precario e Salud Mental. Córdoba: Navajo Editor.

CASSELL, E. J., 1974. An epidemiological perspective of psychosocial factors in disease etiology. American Journal of Medicine, 11:1040-1043.

CASSELL, E. J., 1976a. The Healer's Art. New York: J. P. Lippincott Company.

CASSELL, E. J., 1976b. The nature of suffering and the goals of medicine. New England Journal of Medicine, 11:639-645.

CENTRO DE DEFESA DOS DIREITOS HUMANOS BENTO RUBIÃO, 1994. Favelase as Organizações Comunitárias. Petrópolis: Editora Vozes.

COLLARES, C. A. L. \& M OYSÉS, M. M. A., 1985. Educação ou saúde? Educação $X$ saúde? Educação e saúde. In: Fracasso Escolar: Uma Questão Médica? (C. A. L. Collares \& M. M. A. Moysés, org.), pp.7-16, São Paulo: Cortez/Cedes.

COLLARES, C. A. L.; MOYSÉS, M. M. A. \& LIMA, G. Z., 1985. Saúde escolar e merenda: Desvios do pedagógico? In: Educação e Soci edade (C. A. L. Collares, M. M. A. Moysés \& G. Z. Lima, org.), pp. 1020, São Paulo: Cortez/Cedes.

ENG, E.; HATCH, J. \& CALLAN, A., 1985. Institutionalizing social support through the Church and into the community. Health Educational Quarterly, 1:81-92.

GENRO, T., 1996. O enigma do México. Folha de São Paulo, São Paulo, 25 fev. Caderno I, p.3.

GOTTLIEB, B. H., 1983. Social Support Strategies. Beverly Hills: Sage Publications.

MINKLER, M., 1985. Building supportive ties and sense of community among the inner-city el derly: the Tenderloin Outreach Project. Health Educational Quarterly, 4:303-314.

MINKLER, M ., 1992. Community organizing among the elderly poor in the United States: a case study. Journal of International Health Services, 2:303316.

MOISÉS, J. A., 1982. Contradições urbanas, movimentos sociais e o Estado. In: Cidade, Povo e Poder (J. A. Moisés, org.), pp. 14-29, Rio de Janeiro: Editora Paz eTerra.
OLIVEIRA, L. \& CARDOSO, M., 1995. Mapeando os agentes de saúde na Leopoldina. Se Liga no SINAL. Informativo do Cepel, 23:5.

INFORM ATIVO DO CEPEL, 1993. Problemas que estão no mapa: o Grupo Sementinha. Se Liga no SINAL. Informativo do Cepel, 12:5-6.

TOGNONI, G., 1991. Epidemiologia comunitária. SaludComunitaria, 1:1-6.

VALLA, V. V., 1996a. Educação, Saúde e Cidadania: Uma Releitura da Questão da Medicalização numa Conjuntura de Crise. Plano de trabalho de pós-doutorado. Los Angeles: Center for Health Policy Research, University of California.

VALLA, V. V. , 1996b. A crise de interpretação é nossa. Procurando compreender a fala das classes populares. Educação e Realidade, 21:177-190.

VALLA, V. V., 1997a. Participação popular e saúde: a questão da capacitação técnica no Brasil. In: Participação Popular, Educação e Saúde: Teoria e Prática. (V. V. Valla, E. N. Stotz, org.), pp. 57-90, Rio de Janeiro: Editora Relume-Dumará.

VALLA, V. V., 1997b. Educação popular e conhecimento: a monitorização civil dos serviços de saúde e educação nas metrópoles brasileiras. In: Participação Popular, Educação e Saúde: Teoria e Prática (V. V. Valla \& E. N. Stotz, org.), pp. 105-116, Rio de Janeiro: Editora Relume-Dumará.

VALLA, V. V. \& HOLLANDA, E., 1995. A escola pública: Fracasso escolar, saúde e cidadania. In: Educação, Saú de e Cidadania (V. V. Valla \& E. N. Stotz, org.), pp. 53-86, Petrópolis: Editora Vozes.

VALLA, V. V. \& SIQUEIRA, S. A. V., 1995. O centro municipal de saúde e as necessidades da saúde da população trabalhadora - Encontro ou desencontro? In: Educação, Saúde e Cidadania (V. V. Valla \& E. N. Stotz, org.), pp. 87-98, Petrópolis: Editora Vozes.

VALLA, V. V. \& STOTZ, E. N., 1997. Apresentação. In: Partici pação, Educação e Saúde. Teoria e Prática (V. V. Valla \& E. N. Stotz, org.), p.10, Rio de Janeiro: Editora Relume-Dumará.

VALLA, V. V. \& STOTZ, E. N., 1992. Partici pação PopuIar e Saúde. Petrópolis: Centro de Defesa dos Direitos Humanos (CDDH).

WONG-UN, J. A., 1997. Ética Popular Comunitária, ControledeEndemi as e Exclusão Social: Reflexões a Partir das Organizações deSaúde do NorteAndino Peruano. Dissertação de Mestrado, Rio de Janeiro: Escola Nacional de Saúde Pública, Fundação Oswaldo Cruz. 